\title{
Immobilization and Anaesthesia in Asiatic Lions (Panthera leo persica)
}

\section{Murugan Bharathidasan ${ }^{1}$, Benjamin Justin William ${ }^{2 *}$, Ramamurthy Jayaprakash ${ }^{1}$, Thandavan Arthanari Kannan ${ }^{2}$, Rajarthanam Thirumurugan ${ }^{3}$, Ravi Sundar George ${ }^{1}$}

\author{
${ }^{1}$ Department of Veterinary Surgery and Radiology, Tamil Nadu Veterinary and Animal Sciences University, India; \\ ${ }^{2}$ Centre for Stem Cell Research and Regenerative Medicine, Madras Veterinary College, Chennai-600007, Tamil \\ Nadu, India; ${ }^{3}$ Veterinary Assistant Surgeon, Arignar Anna Zoological Park, Chennai, India.
}

\begin{abstract}
A total of 12 trials were conducted in 8 Asiatic and hybrid lions (Panthera leo persica) for diagnostic and surgical procedures. All the lions were immobilized with a combination of xylazine and ketamine at the rate of 1.00 $\mathrm{mg} / \mathrm{kg}$ and $2.00 \mathrm{mg} / \mathrm{kg}$ body weight, respectively, using darts based on assumed body weight. Ketamine and propofol intravenously were used as induction agents sufficiently to achieve deep plane of anaesthesia and good jaw muscle relaxation in six trials each of treatment I and II. The commercially available large animal endotracheal tubes and custom made silicon medical grade tubes were used for intubation either by direct visualization or by digital palpation of glottis. Anaesthesia was maintained with isoflurane. The study revealed that the young lions required $1.08 \pm 0.10$ and $2.70 \pm 0.26 \mathrm{mg} / \mathrm{kg}$ and adult required $1.06 \pm 0.30$ and $2.64 \pm 0.08 \mathrm{mg} / \mathrm{kg}$ body weight of xylazine and ketamine, respectively for immobilization. Ear flick reflex was taken as an indicator for safe and appropriate time for approaching the lion after immobilization, which was completely abolished only after 1.37 and 2.01 minutes after recumbency in young and adult lions, respectively. Based on the radiographic distance between snout and distal larynx endotracheal tubes of one meter length and $30 \mathrm{~mm}$ diameter were suitable for intubation and the larynx was located between $5^{\text {th }}$ and $6^{\text {th }}$ cervical vertebrae. The dose of ketamine and propofol required for induction was $1.00 \mathrm{mg} / \mathrm{kg}$ and $1.92 \mathrm{mg} / \mathrm{kg}$ body weight, respectively, in immobilized lions and intubation could be safely performed under propofol induction by oropharyngeal digital palpation of glottis for administration of inhalant anaesthetics. Both ketamine and propofol could be used as induction agents in lions immobilized with xylazine-ketamine and for further maintenance with isoflurane.
\end{abstract}

Keywords | Asiatic lions, Anaesthesia, Ear flick reflex, Intubation, Xylazine, Ketamine, Propofol

Editor | Kuldeep Dhama, Indian Veterinary Research Institute, Uttar Pradesh, India.

Received | December 04, 2015; Revised | January 29, 2016; Accepted | January 30, 2016; Published | March 04, 2016

*Correspondence | Benjamin Justin William, Centre for Stem Cell Research and Regenerative Medicine, Madras Veterinary College, Chennai, Tamil Nadu, India; E-mail: vetjust@gmail.com

Citation | Bharathidasan M, William BJ, Jayaprakash R, Kannan TA, Thirumurugan R, George RS (2016). Immobilization and anaesthesia in Asiatic lions (Panthera leo persica). Adv. Anim. Vet. Sci. 4(3): 134-144.

DOI | http://dx.doi.org/10.14737/journal.aavs/2016/4.3.134.144

ISSN (Online) | 2307-8316; ISSN (Print) | 2309-3331

Copyright (c) 2016 Bharathidasan et al. This is an open access article distributed under the Creative Commons Attribution License, which permits unrestricted use, distribution, and reproduction in any medium, provided the original work is properly cited.

\section{INTRODUCTION}

$\mathrm{C}$ hemical immobilization and anaesthesia is an integral component in conservation, diagnostic and surgical procedures in wild animal species. The risks involved in chemical immobilization and anaesthesia in lions are loss of thermoregulation, rigidity, depressed respiration, shock, unpredictable recovery, delayed recovery and convulsions (Wack, 2003; Gunkel and Lafortune, 2008). Commonly used anaesthetic drugs; ketamine and tiletamine often in- duce convulsions in lions. Ketamine has a shorter duration of action and has the disadvantages of poor muscle relaxation, excessive salivation and lack of specific antagonistic to reverse the action. Frequently alpha- 2 adrenergic agonists are combined as adjunct to promote the analgesic action, muscle relaxation, increase the duration of immobilization and to reduce the dose of ketamine (Swan, 1993). Propofol is an alkyl phenol, ultra-short acting non-barbiturate, which readily induces reliable anaesthesia in one armbrain circulation. 
Inhalant anaesthetics are safe for long-term anaesthesia due to the merit of less stress, smooth and short recovery, ease in change of depth of anaesthesia and possibility of adopting resuscitative methods at times of emergency. Relatively complicated anatomy and position of the larynx at the level of $5^{\text {th }}$ cervical vertebrae and structures in the pharynx (Weissengruber et al., 2002) always make the task of intubation more difficult, apart from added fear in lions and other members of genus Panthera when compared with domestic cats.

The study was designed to assess the reliability of ear tactile reflex as an indicator to assess the depth of anaesthesia in lions immobilized with xylazine and ketamine combination and suitability of ketamine/propofol with isoflurane for anaesthesia in Asiatic and hybrid lions.

\section{MATERIALS AND METHODS}

The study was conducted in Asiatic lions (Panthera leo persica) and hybrid lions housed in Arignar Anna Zoological Park, Vandalur, Chennai and referred to the Department of Veterinary Surgery and Radiology, Madras Veterinary College Teaching Hospital for various diagnostic and surgical procedure. A total of 12 trials were conducted in 8 Asiatic lions; which involved 4 trials with 2 young lions within 2 to 4 years of age and 8 trials with 6 adult above 6 years of age (Schaller, 1972). The study was conducted in accordance with Indian Wild Animal Protection Law 1972, amended in 1992. The procedure was also approved by the Dean, Faculty of Veterinary Science, Tamil Nadu Veterinary and Animal Sciences University. The procedures performed were radiography of hip, thorax, digits and tibia, wound dressing and bandaging and surgical procedures like vasectomy, tail amputation and phacoemulsification and extraction of cataract lens. The animals included in the study were apparently healthy and assessed for their fitness based on physical status and behaviour before immobilization and anaesthesia. The animals intended for elective procedures were visited two days prior to the study and their physical condition, feeding and voiding habits were observed. Previous history of any ailment, deworming schedule and vaccination schedule were taken into account. The weight of the lions ranged from 90 to $145 \mathrm{~kg}$.

\section{IMMOBILIZATION}

The lions were confined in cages 24 hours prior to the procedure and feed was withheld; but free access to water was allowed (Epstein et al., 2002). All the lions were immobilized with a mixture of xylazine hydrochloride $(1.00 \mathrm{mg} / \mathrm{kg})$ and ketamine hydrochloride $(2.50 \mathrm{mg} / \mathrm{kg})$, intramuscularly in the upper hind limb or shoulder area (Meltzer, 1999) using blowgun, based on the assumed body weight. Dose of xylazine and ketamine with respect to actual weight, time taken for in-coordination and ataxia, time for recumbency and quality of immobilization were compared between young and adult lions. The quality of immobilization was graded as 1 (excellent), 2 (good), 3 (fair) and 4 (poor) on the basis of ataxia, attempts for sternal recumbency, symptoms of CNS stimulation, stumbling and requirement of additional dose of immobilizing agents (Wenger et al., 2010).

\section{EAR Flick RefleX}

Once the animals attained lateral recumbency, they were approached from outside the cage and the pinna was gently stimulated with a stick, sufficiently to stretch the auricular muscles to elicit the ear twitch reflex (Figure 1) and the ear flick reflex was scored (Gatesman and Wiesner, 1982). Score 1: Unsatisfactory - The animal could actively move its limb and even stand up when the ear pinna was stimulated, Score 2: Light level - Ear twitch was present and feeble movements could be noticed and Score 3: Satisfactory - Absence of ear twitch reflex. Additional incremental doses of xylazine and ketamine were administered to achieve recumbency and immobilization characterized by absence of ear flick reflex, if required. The time taken in minutes for complete absence of ear flick reflex following darting was recorded.The data were compared between the young and adult lions.

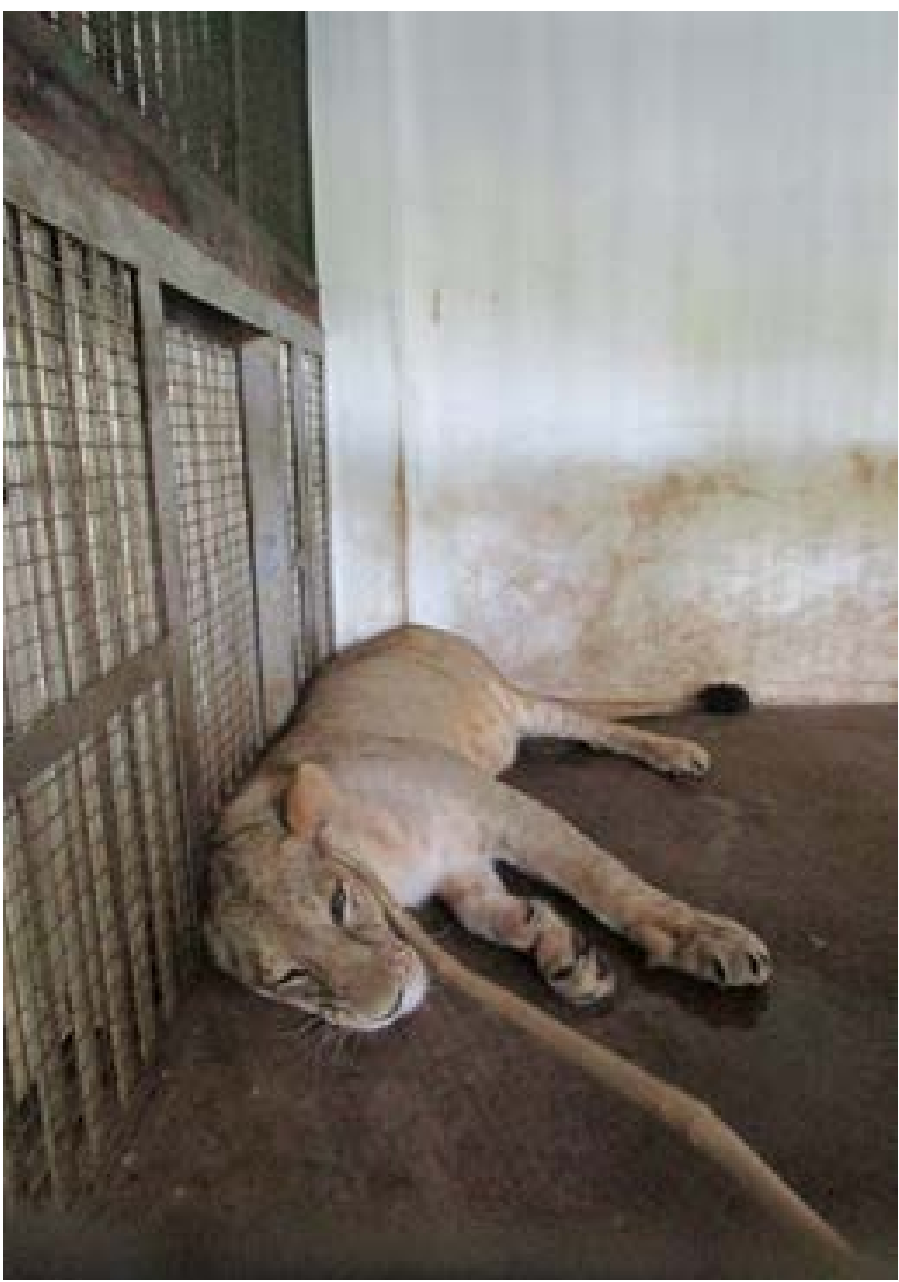

Figure 1: Stimulation of ear flick reflex after immobilization 
Handling, Safety Measures and Transportation The immobilized lions were blind folded and the fore limbs were hobbled (Wenger et al., 2010; Kock and Burroughs, 2012). Intravenous catheters (18 gauge) were fixed either in cephalic or saphenous vein. The actual weights of the lions were recorded and the lions were transported to the Zoo Veterinary Hospital for further procedures.

\section{RADIOGRAPHIC MoRPHOLOGY OF LARYNX AND} Trachea and Selection of Endotracheal Tube All the immobilized lions were subjected to survey radiography of neck and thorax through lateral projection (Figure 2). Using survey radiography, position of the larynx in relation to cervical vertebrae, length and width of larynx, distance between larynx and carina and the outer diameter $(\mathrm{cm})$ behind the larynx, thoracic inlet, mid thorax and before carina were measured. Distance between the snout of upper lip and glottis was measured through oropharynx $(\mathrm{cm})$.

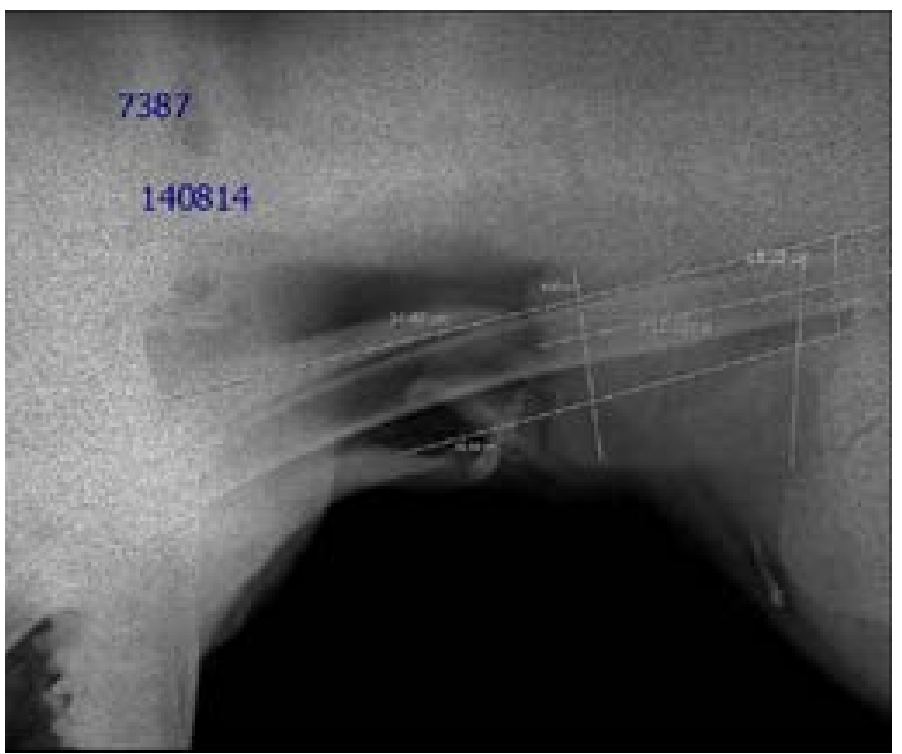

Figure 2: Radiographic measurements-Position of larynx

Large animal cuffed rubber endotracheal tubes with inner diameter 20 to 24 millimeters, (mm ID) and silicon flexible medical grade tubes of 24 to $38 \mathrm{~mm}$ ID custom made plain endotracheal tubes were used for intubation after smearing them with lidocaine gel. The distal ends of the endotracheal tubes were positioned behind the larynx. The diameter and length of endotracheal tubes for intubation were selected based on the tracheal diameter and distance between the snout of the upper lip and distal larynx, respectively.

\section{INDUCTION}

Anaesthesia in the lions allotted to groups I and II was induced with the intravenous administration of ketamine or propofol at calculated dose of 2.00 and $1.00 \mathrm{mg} / \mathrm{kg}$ body weight, respectively, to achieve jaw muscle relaxation; suf- ficient for intubation. No anaesthetic was administered in lions, which were already in the surgical plane of anaesthesia with the immobilization doses of xylazine and ketamine and they were allotted to treatment I. The induction dose of ketamine and propofol required to abolish pedal reflex and to effect complete jaw muscle relaxation was calculated. The quality of induction was scored (Wenger et al.,2010) between 1 and 6 and compared between treatments (Score 1: Limited effect - re-dosing required for recumbency. Risk of injury to the handler, Score 2: Deep sedation - spontaneous motor activity, struggling during manipulation, presence of anal or palpebral reflex, responsive to painful stimuli, Score 3: Light anaesthesia level muscular rigidity, absence of anal reflex but slow palpebral reflex, voluntary tail movements and can be handled safely, Score 4: Moderate anaesthesia level - smooth, complete relaxation, extractable tongue, loss of pedal reflex, no involuntary tail movements, no reaction to blood sampling and safe handling, Score 5: Surgical anaesthesia level - smooth, complete relaxation, extractable tongue, loss of palpebral reflex and jaw tone, no involuntary tail movements, no reaction to blood sampling, safe handling and Score 6 - Too deep, absence of reflexes, cardio-respiratory depression).

\section{INTUBATION TECHNIQUE}

Oro tracheal Intubation was performed; 6 trials each in direct visualization and digital palpation of glottis, irrespective of the treatment group. For direct visualization the lions were positioned in sternal recumbency and the neck was extended cranially. The jaws were opened with the help of straps sufficiently and attempted to visualize the glottis. The lions were intubated using endotracheal tubes blindly (Figure 3).

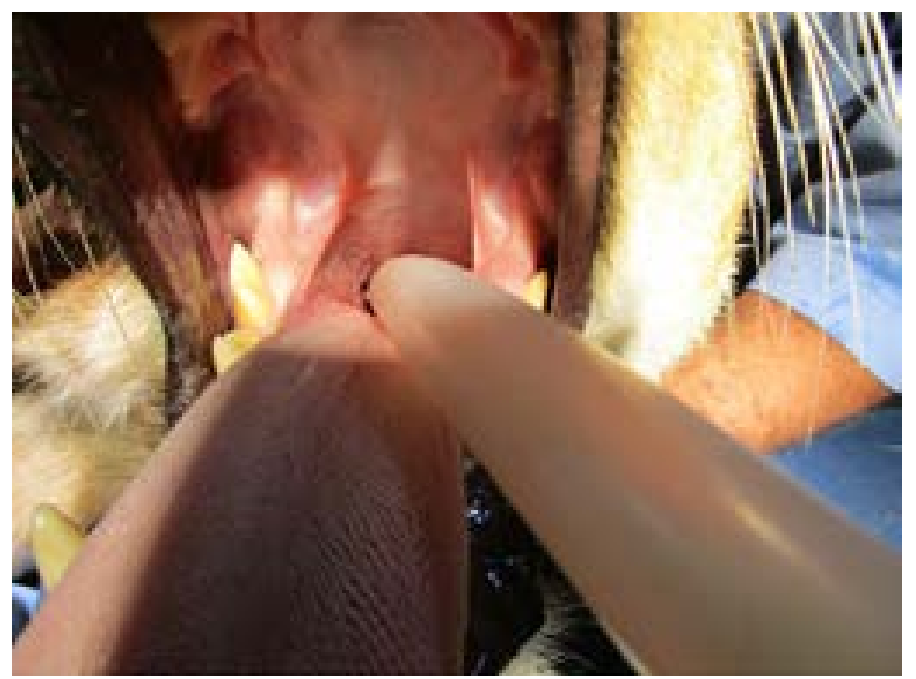

Figure 3: Intubation by visualization of glottis

Digital intubation was performed by opening the jaws with the aid of straps. The endotracheal tube was directed into the larynx with the hand of the anaesthetist cuffed over the end of the tube and passed through the mouth and 
Table 1: The intubation difficulty scale (IDS) for scoring techniques of intubation by digital palpation of glottis and direct visualization of glottis using silicon and rubber endotracheal tubes

\begin{tabular}{|c|c|c|}
\hline Variable & Description & Score \\
\hline $\mathrm{N}_{1}$ & $\begin{array}{l}\text { The number of supplementary attempts, an attempt -defined as one advancement of the } \\
\text { tube in the direction of the glottis during direct laryngoscopy or one like advancement of } \\
\text { the tube in the case of a blind intubation trial. }\end{array}$ & $\begin{array}{l}\text { Every additional attempts adds } \\
1 \text { point }\end{array}$ \\
\hline $\mathrm{N}_{2}$ & $\begin{array}{l}\text { The number of supplementary operator; } \mathrm{N}_{2} \text { represents the number of additional persons } \\
\text { directly attempting (i.e. not assisting) intubation. }\end{array}$ & $\begin{array}{l}\text { Each additional operator adds } \\
1 \text { point }\end{array}$ \\
\hline $\mathrm{N}_{3}$ & $\begin{array}{l}\text { The number of alternative techniques used. For example, changing from an oral intu- } \\
\text { bation to blind nasotracheal intubation or curved blade to straight blade increases } \mathrm{N}_{3} \\
\text { by } 1 \text { point. The various techniques used should be noted in chronological order, so that } \\
\text { subsequent identification of techniques ineffective in a particular case (or series) may be } \\
\text { undertaken }\end{array}$ & $\begin{array}{l}\text { Each alternative technique } \\
\text { adds } 1 \text { point (repositioning } \\
\text { of patient, change of tube, } \\
\text { addition of stylette, change in } \\
\text { approach) }\end{array}$ \\
\hline $\mathrm{N}_{4}$ & $\begin{array}{l}\text { Glottic exposure as defined by the Cormack grade minus one; grade I }\left(\mathrm{N}_{4}=0\right) \text { on this } \\
\text { scale corresponds to complete visualization of the vocal cords, grade II }\left(\mathrm{N}_{4}=1\right) \text { to } \\
\text { visualization of the inferior portion of the glottis, grade III }\left(\mathrm{N}_{4}=2\right) \text { to visualization of } \\
\text { only the epiglottis and grade IV }\left(\mathrm{N}_{4}=3\right) \text { to a nonvisualized epiglottis. Glottic exposure is } \\
\text { evaluated during the first attempt by the first operator. In case of successful intubation, } \mathrm{N}_{4} \\
0 \text {. If the blind attempt (s) fail, glottis exposure is evaluated during the first subsequent } \\
\text { alternative visualized laryngoscope attempt. }\end{array}$ & $\begin{array}{l}\text { Apply Cormack grade }\left(\mathrm{N}_{4}=0\right) \\
\text { for successful blind intubation }\end{array}$ \\
\hline $\mathrm{N}_{5}$ & $\begin{array}{l}\text { The lifting force applied during laryngoscopy; } \mathrm{N}_{5}=1 \text { if subjectively increased lifting force } \\
\text { is necessary. This notion is based on the operator's impression that an abnormal amount } \\
\text { of force was used compared with routine practice. }\end{array}$ & \\
\hline $\mathrm{N}_{6}$ & $\begin{array}{l}\text { The necessary for applied external laryngeal pressure to optimized the glottis exposure; } N_{6} \\
=0 \text { if no external pressure is applied. } N_{6}=1 \text { if external laryngeal pressure is necessary. }\end{array}$ & \\
\hline $\mathrm{N}_{7}$ & $\begin{array}{l}\text { Position of the vocal cords; } \mathrm{N}_{7}=0 \text { if the vocal cords are in abduction. } \mathrm{N}_{7}=1 \text { if the vocal } \\
\text { cords are in adduction presenting an impediment to tube passage. }\end{array}$ & \\
\hline
\end{tabular}

pharyngeal region. The tube was passed into the trachea after depressing the epiglottis with fingers (Figure 4).

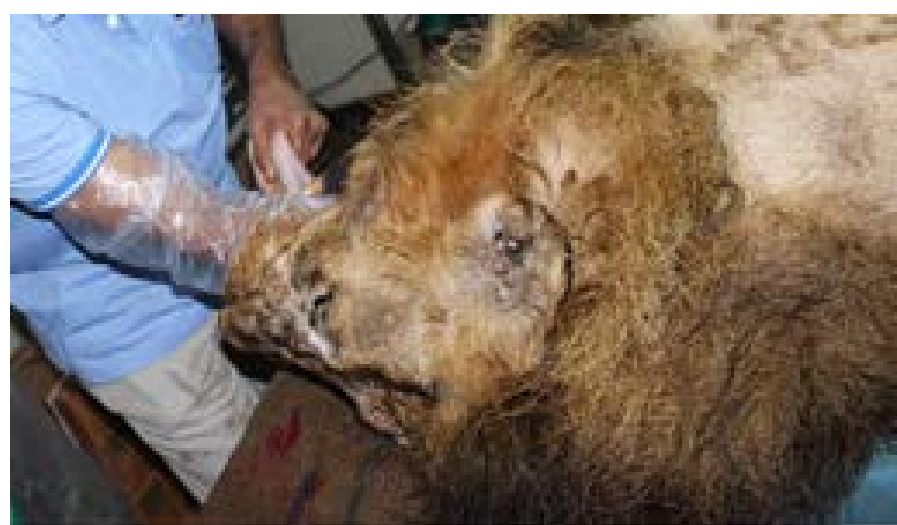

Figure 4: Digital palpation of glottis for intubation

The difficulty in intubation was scored based on the intubation difficulty scale (IDS) evolved by Adnet et al. (1997) for intubation of rubber endotracheal tubes in human (Table 1).

The endotracheal tubes were secured by a locally fabricated wooden mouth gag which was positioned between the jaws. The lions were maintained anaesthesia using isoflurane at a concentration ranging from 0.5 to $2.00 \%$ in oxygen. The concentration of isoflurane and the period of anaesthetic maintenance in minutes were recorded.

Monitoring

The time taken for early orientation characterized by head, neck and fore limb movements, time taken for complete recovery and quality of recovery were recorded from the time of discontinuation of administration of isoflurane. The quality of recovery was scored (Wenger et al., 2010) between 1 and 4 based on transition from lateral to sternal recumbency, ataxia, number of attempts to stand and nature and duration of recovery.

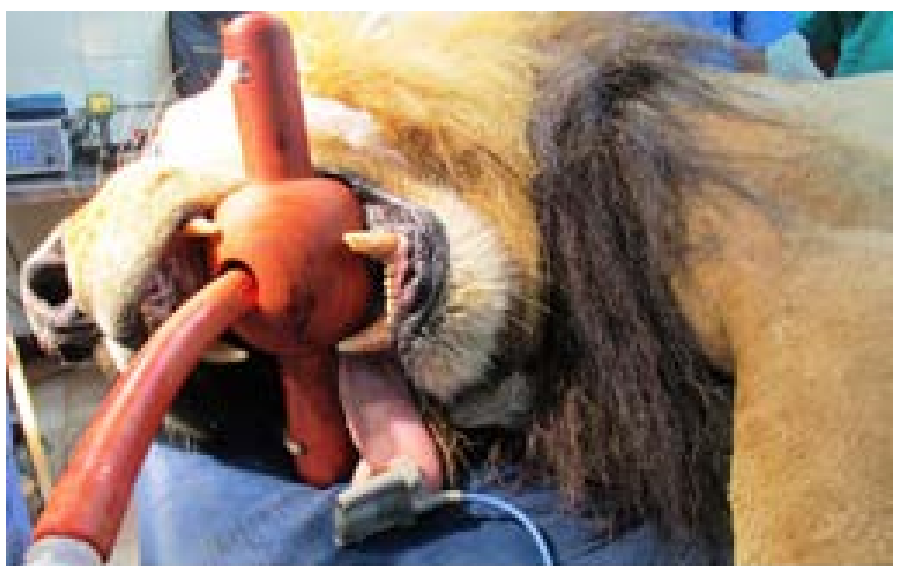

Figure 5: Intubated - Cuffed endotracheal tube with wooden mouth gag in position 
Rectal temperature in degrees Celsius $\left({ }^{\circ} \mathrm{C}\right)$, heart rate, respiration rate, electrocardiogram and saturated percentage of oxygen were recorded after immobilization, after induction, during maintenance (Figure 6) and before release into the cage (before recovery) and compared between groups.

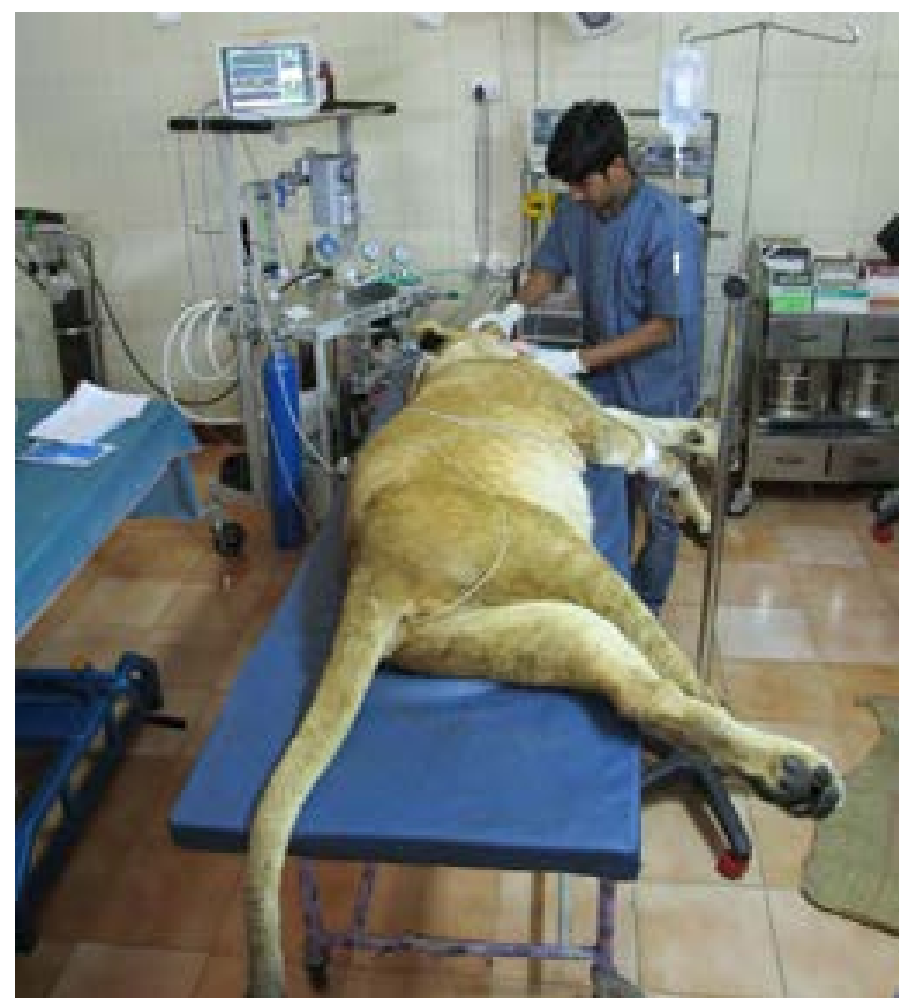

Figure 6: Monitoring of anaesthesia with vital signs monitor

\section{RESULTS}

\section{IMMOBILIZATION}

The dose of xylazine and ketamine required for immobilization in young lions $(1.08 \pm 0.10$ and $2.70 \pm 0.26 \mathrm{mg} / \mathrm{kg}$ body weight) was significantly higher $(p<0.01)$ than that required for adult lions $(1.06 \pm 0.30$ and $2.64 \pm 0.08 \mathrm{mg} /$ $\mathrm{kg}$ body weight). The doses of xylazine and ketamine required for immobilization in male lions $(1.08 \pm 0.07$ and $2.71 \pm 0.16 \mathrm{mg} / \mathrm{kg}$ body weight) were significantly higher dose $(\mathrm{p}<0.05)$ than that in female lions $(1.04 \pm 0.40$ and $2.61 \pm 0.10 \mathrm{mg} / \mathrm{kg}$ body weight).

The mean $\pm \mathrm{SE}$ of time for attaining in-coordination and ataxia after darting in young and adult lions was $2.50 \pm 0.29$ and $3.00 \pm 0.35 \mathrm{~min}$, respectively, with significant variations $(\mathrm{p}<0.01)$.

The mean $\pm \mathrm{SE}$ of time for recumbency after darting was $7.13 \pm 0.77$ and $6.18 \pm 0.40 \mathrm{~min}$ in young and adult lions respectively $(\mathrm{p}>0.05)$.

The mean $\pm \mathrm{SE}$ of the grade for quality of immobilization in young and adult lions was $2.25 \pm 0.48$ and $2.00 \pm 0.27 \mathrm{~min}$, respectively. The animals were ataxic and made more than one attempt to sit and lie down in both the age groups. No incidence of stimulation of central nervous system and risk of injury was noticed; revealing that the quality of induction was fair to good in the lions that were immobilized.

In both young and adult lions immediately after recumbency the score for ear flick reflex varied between one and two characterized by ear twitch, turning of head and fore limb movement which indicated persistence of ear flick reflex at unsatisfactory or light levels. Two young lions required additional dose of xylazine and ketamine to abolish the ear flick reflex and the time taken for abolishing ear flick reflex was significantly $(\mathrm{p}<0.01)$ high in young $(8.50 \pm 1.50 \mathrm{~min}-$ utes) compared to adult lions $(8.19 \pm 0.48$ minutes).

\section{Radiographic Morphology of LarynX and}

\section{Trachea and Selection of Endotracheal tubes}

The distance between the snout of the upper lip and glottis measured through oropharynx was $60.48 \pm 0.99$ and $66.05 \pm 0.99 \mathrm{~cm}$ and the radiographic length of the larynx was and $16.24 \pm 0.39$ and $16.85 \pm 0.28 \mathrm{~cm}$ respectively in the young and adult Asiatic lions of the study. The total length between the snout of the upper lip and distal larynx was 76.72 and $82.90 \mathrm{~cm}$ in young and adult lions.

The mean $\pm \mathrm{SE}$ of the radiographic width of the larynx was $9.20 \pm 0.16$ and $9.72 \pm 0.67 \mathrm{~cm}$ respectively in young and adult lions. The mean \pm SE tracheal outer diameters of both young and adult lions was $5.57 \pm 0.20,5.95 \pm 0.18$, $5.76 \pm 0.24$ and $5.83 \pm 0.22 \mathrm{~cm}$ behind larynx, at thoracic inlet, mid thorax and proximal to carina, respectively.

The smallest outer diameter of trachea was $4.58 \mathrm{~cm}$ behind the larynx in a young lion and the maximum outer diameter was $5.90 \mathrm{~cm}$ in an adult lion at mid thorax. The mean \pm SE of the length of trachea behind larynx to carina was $44.56 \pm 0.77$ and $45.84 \pm 0.67 \mathrm{~cm}$ in young and adult lions $(\mathrm{p}>0.05)$.

The study revealed that the position of the larynx varied and located between $5^{\text {th }}$ and $6^{\text {th }}$ cervical vertebrae in both young and adults lions. The distance between snout of the upper lip and distal larynx was $76.72 \mathrm{~cm}$ and $82.90 \mathrm{~cm}$ in young and adult lions, respectively. The trachea was narrow at distal to the larynx and was $4.58 \mathrm{~cm}$ in a young lion. Commercially available large animal cuffed endotracheal tubes $24 \mathrm{~mm}$ ID and $90 \mathrm{~cm}$ length $30 \mathrm{~mm}$ ID medical grade silicon tubes custom made as plain endotracheal tubes were used for intubation.

\section{INDUCTION}

The dose of ketamine required for induction was $1.92 \mathrm{mg} /$ $\mathrm{kg}$ body weight in group I and the dose of propofol required was $1.00 \mathrm{mg} / \mathrm{kg}$ body weight in group II lions, intravenously. 
The quality of induction in group I lions was between light and surgical plane of anaesthesia with a mean score of $4.00 \pm 0.26$ and characterized by muscular rigidity, retraction during extraction of tongue and persistent or sluggish pharyngeal reflex during digital palpation of glottis. The quality of induction in group II lions was between moderate and surgical plane of anaesthesia with a score of $4.50 \pm 0.22$ and characterized by absence of pharyngeal reflex, extractable tongue and complete relaxation of jaw muscles.

\section{INTUBATION}

Intubation was performed by visualization of glottis and digital palpation of glottis using rubber and silicon medical grade tubes after ascertaining the diameter and length of tube to be intubated and positioned distal to larynx based on radiographic findings. The mean $\pm \mathrm{SE}$ scores of the Intubation difficulty scale (IDS) variables $\mathrm{N}_{1} \mathrm{~N}_{2} \mathrm{~N}_{3} \mathrm{~N}_{4}$, $\mathrm{N}_{5}, \mathrm{~N}_{6}$ and $\mathrm{N}_{7}$ were $2.667 \pm 0.33,1.333 \pm 0.33,2.000 \pm 0.58$, $2.000 \pm 0.58,0.667 \pm 0.33,0.667 \pm 0.33$ and $0.667 \pm 0.33$ when rubber endotracheal tubes were intubated under direct visualization of glottis, $2.667 \pm 0.33,2.000 \pm 0.58,3.000 \pm 0.56$, $2.000 \pm 0.00,1.000 \pm 0.00,0.667 \pm 0.33$ and $1.000 \pm 0.00$ when silicon endotracheal tubes were intubated under direct visualization of glottis, $0.000 \pm 0.00,0.000 \pm 0.00,0.000 \pm 0.00$, $0.000 \pm 0.00, \quad 0.000 \pm 0.00, \quad 0.000 \pm 0.00$ and $0.333 \pm 0.33$ when rubber endotracheal tubes were intubated through digital palpation of glottis and $0.333 \pm 0.33,0.000 \pm 0.00$, $0.000 \pm 0.00, \quad 0.000 \pm 0.00, \quad 0.000 \pm 0.00, \quad 0.000 \pm 0.00$ and $0.333 \pm 0.33$ when custom made silicon medical grade tubes were intubated through digital palpation technique.

Statistical analysis of the IDS score showed highly significant variation $(p<0.01)$ between the techniques of intubation; revealing direct visualization of glottis and intubation was more difficult in Asiatic lions when compared with digital palpation and intubation.

The diameter of the central body of the gag was sufficient to fit between the upper and lower jaws behind the incisors and the intubated tube could be secured in position. Further it provided sufficient space between the commissures of the jaws to keep the tongue out without obstructing the airway.

\section{Maintenance}

The mean $\pm \mathrm{SE}$ of duration of maintenance of anaesthesia was $57.60 \pm 0.12$ and $52.80 \pm 0.06$ minutes in group I and II lions. During anaesthesia the concentration of isoflurane was maintained between 0.50 and 2.00 per cent in 100 per cent oxygen as carrier gas in circle system.

\section{RECOVERY}

The mean \pm SE of time for early orientation after discontinuation of administration of isoflurane was $10.83 \pm 0.75$ $\mathrm{min}$ in group I and 12.50 $\pm 0.76 \mathrm{~min}$ in group II lions. Statistical analysis revealed no significant variation $(p>0.05)$ between groups.

The mean $\pm \mathrm{SE}$ of time taken for unassisted standing was $16.67 \pm 0.80 \mathrm{~min}$ in group I and $27.50 \pm 2.14 \mathrm{~min}$ in group II lions with significant variation $(\mathrm{p}<0.05)$ between groups.

The grade for the quality of recovery was $1.67 \pm 0.21$ in group I and $2.83 \pm 0.31$ in group II lions. In both the groups of lions the recovery varied from fair to excellent. The incidence of severe ataxia of hind limbs, more number of attempts to stand and time duration more than 30 minutes were noticed in group II lions. Stormy recovery was not noticed in both the groups.

\section{MONITORING}

The mean $\pm \mathrm{SE}$ of rectal temperature in degrees Celsius $\left({ }^{\circ} \mathrm{C}\right)$ after immobilization, after induction, during maintenance and before recovery was $38.47 \pm 0.11,38.43 \pm 0.10$, $38.07 \pm 0.07$ and $38.20 \pm 0.10$ in group I and $38.60 \pm 0.14$, $38.53 \pm 0.08,37.40 \pm 0.12$ and $37.33 \pm 0.10$ in group II lions, respectively. Statistical analysis revealed highly significant $(\mathrm{p}<0.01)$ decrease in the mean rectal temperature during maintenance and before recovery in both the groups.

The mean $\pm \mathrm{SE}$ of heart rate per minute after immobilization, after induction, during maintenance and before recovery was $54.50 \pm 1.40,56.67 \pm 1.08,50.00 \pm 0.52$ and $57.00 \pm 0.86$ in group I and $56.83 \pm 1.28,57.00 \pm 0.68$, $54.33 \pm 0.6155 .33 \pm 0.67$ in group II lions, respectively. Statistical analysis revealed highly significant $(\mathrm{p}<0.01)$ decrease in mean heart rate in group I and non-significant $(\mathrm{p}$ $>0.05)$ decrease in group II during maintenance of anaesthesia. The mean heart rate increased $(p<0.01)$ in both the groups before recovery.

The mean $\pm \mathrm{SE}$ of respiratory rate after immobilization, after induction, during maintenance and before recovery was $24.83 \pm 1.51,21.83 \pm 0.75,19.33 \pm 0.67$ and $24.33 \pm 0.80$ in group I and $26.00 \pm 0.73,23.00 \pm 0.86,21.00 \pm 1.53$ and $24.00 \pm 0.89$ in group II lions, respectively. Statistical analysis revealed highly significant $(\mathrm{p}<0.01)$ reduction in mean respiratory rate after induction and during maintenance in both groups. The mean respiratory rate increased in both groups before recovery.

The mean $\pm \mathrm{SE}$ of $\mathrm{SpO}_{2}$ after immobilization, after induction, during maintenance and before recovery was $96.50 \pm 0.67,90.83 \pm 1.47,98.17 \pm 1.49$ and $92.83 \pm 0.75 \%$ in group I and $95.67 \pm 1.20,93.33 \pm 1.52,95.17 \pm 1.19$ and $92.50 \pm 0.72 \%$ in group II lions, respectively. Statistical analysis revealed significant $(\mathrm{p}<0.01)$ reduction in mean $\mathrm{SpO}_{2}$ in both the groups after induction and before recovery. When the mean $\mathrm{SpO}_{2}$ percentage was compared 
between groups during maintenance group I maintained higher $(\mathrm{p}<0.01)$ mean percentage.

The electrocardiographic studies at various intervals revealed sinus rhythm without changes in the configuration. Reduction in heart rate was observed during maintenance and before recovery in both the groups.

\section{DISCUSSION}

\section{IMMOBILIZATION}

Xylazine-ketamine combination as cocktail has received widespread use as chemical immobilizing drugs for non-domestic carnivores.

Young lions took significantly $(\mathrm{p}<0.05)$ lesser time for in-coordination and ataxia after darting when compared with adult lions which could be attributed to the higher dose of xylazine-ketamine required in young lions for immobilization than adult lions.

The mean dose of ketamine used in the study ranged from 2.61 to $2.71 \mathrm{mg} / \mathrm{kg}$ body weight intramuscularly and was less than the doses reported earlier (Epstein et al., 2002) where ketamine was used maximum upto a dose of $10 \mathrm{mg} /$ $\mathrm{kg}$ body weight. The dose of ketamine used in the present study concurred with previous reports (Van Wyk and Berry, 1986; Stander and Morkel, 1991; Quandt, 2005; Tomizawa et al., 1997; Fahlman, 2008) in African lions.

The time taken for ataxia and recumbency concurred with the previous reports (Olatunji-Akioye et al., 2010; Wenger et al., 2010). The shorter time for immobilization and fair to good score for the quality of immobilization could be attributed to preanaesthetic fasting and calm environment (Epstein et al., 2002; Vesal and Naeini, 2007). Quandt (2005) observed sudden recoveries without warning, bradycardia and vomiting following medetomidine and ketamine immobilization in lions. Fahlman (2005) reported many disadvantages following administration of ketamine; such as muscle spasms, convulsions and excessive salivation. Xylazine as an adjunct masked the deleterious effects and potentiated the beneficial effects of ketamine (Van Wyk and Berry, 1986 and Fahlman, 2008).

Wild felids were assessed for the absence of ear flick reflex after chemical immobilization as an indicator of appropriate time for the handlers or veterinarian to approach the animal. Gatesman and Wiesner (1982) explained the technique of assessing the depth of immobilization and categorized the level of immobilization into various planes.

Immediately after recumbency the score for ear flick reflex varied between 1 and 2 characterized by ear twitch, turning of head and fore limb movement; indicating persistence of ear flick reflex at unsatisfactory or light levels and it was considered as unsafe to approach the lions as even visual stimuli could arose them.

The study revealed that the lions should not be approached immediately after recumbency following immobilization. The absence of ear flick reflex could be an indicator for safe approach for which the time factor between recumbency and absence of ear flick reflex and the requirement of further incremental doses of xylazine and ketamine to abolish the ear flick reflex should be considered judiciously.

\section{Radiographic Morphology of LaRynx and} Trachea and Selection of Endotracheal Tubes Radiographic morphology of larynx and trachea was studied with the objective of identifying the optimal length and diameter of the endotracheal tube to be used in Asiatic lions. Generally the largest diameter endotracheal tube that would easily fit through the arytenoid cartilages without damaging them was selected to minimize resistance and the work of breathing. The length of the endotracheal tube was determined in such that the distal tip of the tube was positioned midway between the larynx and the thoracic inlet (Bednarski et al., 2011).

The topographic position of the larynx in Asiatic lions was between $5^{\text {th }}$ and $6^{\text {th }}$ cervical vertebrae and was similar to African lions described (Weissengruber et al., 2002); whereas in domestic cats the basihyoideum of the pharynx located ventral to the cranial base or the atlas. It was observed that the pharyngeal wall showed numerous longitudinal folds on its inner surface in addition to the muscles and numerous collagenous and elastic fibres within the lateral pharyngeal walls and the soft palate. The distance between upper lip and glottis observed in Asiatic lions was longer than the reported values for African lion, because the age of the African lion dissected and reported was under one year age (Weissengruber et al., 2002).

Titze et al. (2010) described that the trachea of wild felids had two distinct paths. First the open dorsal (posterior) portion - the pars membraneaceus which was quite large and drum like. This might allow large bolus of food to pass down the epiglottis, protruding into the tracheal cavity during swallowing. The second: the tracheal rings that allow a large degree of telescoping such that the trachea could be collapsed or extended. Weissengruber et al. (2002) stated that the cervical part of the trachea was short with overlapping tracheal cartilages in African lions.

The size of endotracheal tube based on radiographic finding in the present study differed from earlier reports (Epstein et al., 2002; Vesal and Naeini, 2007; Gunkel and Lafortune, 2008; Steeil et al., 2012) who had used 16 to 24 $\mathrm{mm}$ inner diameter cuffed endotracheal tubes in African 
lions. In the present study medical grade silicon custom made endotracheal tubes of $30 \mathrm{~mm}$ ID could be easily intubated. The study revealed that the plain endotracheal tubes of $30 \mathrm{~mm}$ ID and above with one meter length was the minimum requirements for intubating young and adult Asiatic lions. Bednarski et al. (2011) recommended plain un-cuffed endotracheal tubes in felids and should never be rotated inside the trachea while changing the position of the animals; that might cause tracheal tears.

\section{INDUCTION}

The dose of ketamine and propofol required for induction was $1.92 \mathrm{mg} / \mathrm{kg}$ and $1.00 \mathrm{mg} / \mathrm{kg}$ body weight intravenously respectively. The dose of ketamine used for induction in the present study was lesser than that suggested by $\mathrm{Ve}$ sal and Naeini (2007), who recommended the use of 2 to $3 \mathrm{mg} / \mathrm{kg}$ body weight xylazine and 7 to $10 \mathrm{mg} / \mathrm{kg}$ body weight ketamine for induction of anaesthesia in lions. The induction dose of ketamine in the present study was lesser as already the lions were immobilized. The dose of ketamine for induction in the present study was comparable with the doses reported earlier reports (Hashizaki et al., 1998; Epstein et al., 2002; Ali, 2005; Fahlman et al., 2005; Sontakke et al., 2009; Steeil et al., 2012; Leonardi et al., 2014). As already the lions were immobilized with xylazine and ketamine they required less dose of ketamine.

Epstein et al. (2002) administered propofol at the rate of $1 \mathrm{mg} / \mathrm{kg}$ body weight intravenously in immobilized lions and reported that propofol provided smooth and uneventful anaesthesia. As propofol was detoxified in the body tissue and only 10 per cent of the drug depended on liver for detoxification, it could be a safe anaesthetic in old and sick animals and those with liver and renal problems.

Although propofol might be more expensive the induction dose used in this study was relatively low, making its use economically feasible. It could be concluded that propofol could be used as a safe anaesthetic in immobilised lions and oropharynx intubation by digital palpation of glottis could be performed safely under deep plane of anaesthesia.

\section{INTUBATION}

Two intubation techniques were studied in Asiatic lions - direct visualization of glottis and intubation and digital palpation of glottis through oropharynx and intubation. The difficulties faced in direct visualization and intubations were the anatomical location of the larynx at the level of $5^{\text {th }}$ to $6^{\text {th }}$ cervical vertebrae in Asiatic lions, similar to African lions (Weissengruber et al., 2002). The soft palate terminated dorsal to the epiglottis which could hardly be moved ventrally in lions. It was observed that the pharyngeal wall was elongated and showed numerous longitudinal folds on its inner surface in addition to the muscles and numerous collagenous and elastic fibres within the lateral pharyngeal walls and the soft palate. Also the distance between upper lip and larynx in young and adult lions was 76.72 and $82.90 \mathrm{~cm}$ respectively. Limited published literature was available on intubation and maintenance of anaesthesia using inhalant agents in lions. Epstein et al. (2002), Vesal and Naeini (2007), Gunkel and Lafortune (2008) and Steeil et al. (2012) had used 16 to 24 millimetre inner diameter endotracheal tubes in African lions under direct visualization which were comparatively smaller in size when comparing the size of the trachea distal to larynx (above 4 centimetres) and was the narrow region in the trachea. Smaller size endotracheal tubes were easier to insert, but larger size tubes have less airway resistance and allow for better suctioning and less work of breathing. A stylet could be used to guide intubation, but stylets were associated with pharyngeal or laryngeal trauma.

The alternative technique evolved in the study was to intubate by digital palpation of glottis through oropharynx by inserting gloved hand. The endotracheal tube was inserted by covering its distal end with hand and after reaching the larynx the rima glottis was located with finger and the tube was introduced to locate the distal end behind the larynx. This procedure could easily be performed in lions which were induced at surgical plane of anaesthesia with good relaxation of jaw muscles, extractable tongue and absence of laryngeal reflex.

In lions induced with ketamine, the pharyngeal reflex and retraction of tongue were noticed, making intubation fearful and difficult. Whereas when the lions were induced with propofol relaxation of jaw muscles was good with extractable tongue and absence of pharyngeal reflex making intubation easy and safe.

Considering the local availability and cost, medical grade silicon endotracheal tubes were used in the study as disposable endotracheal tubes.

In the present study the overall total IDS score was 10.00 and 12.33 for cuffed rubber and un-cuffed silicon endotracheal tubes intubated by direct visualization of glottis and 0.333 and 0.666 for cuffed rubber and un-cuffed silicon endotracheal tubes intubated by digital palpation of glottis. The lesser difficulty score in rubber endotracheal tubes was due to the smaller size $(24 \mathrm{~mm})$.

Digital palpation of glottis under adequate anaesthetic depth and intubation was the ideal procedure for intubating Asiatic lions.

\section{Maintenance}

Vesal and Naeini (2007) Inhalant anaesthetics were recommended in lions for long term procedure. Gunkel and Lafortune (2008) and Steeil et al. (2012) reported the 
use of isoflurane as maintenance agent in lions at varying vaporizer settings between 0.5 to 4.0 per cent. In the present study the isoflurane concentration was maintained between 0.5 to 2.0 per cent. 100 per cent oxygen was used as carrier gas and the flow rate was maintained at 10 to 15 $\mathrm{ml} / \mathrm{kg}$ body weight as tidal volume.

The time for unassisted standing was $16.67 \pm 0.80$ and $27.50 \pm 2.14$ minutes in lions induced with ketamine and propofol and the time for unassisted standing was prolonged in lions induced with propofol significantly ( $\mathrm{p}$ $<0.05$ ). The lions induced with propofol made few attempts to stand but frequently fall before being successful and displayed marked ataxia with incidence of hind limb staggering in two cases.

The score for the recovery in lions induced with ketamine and propofol were $1.67 \pm 0.21$ and $2.83 \pm 0.31$ respectively revelling smooth and early recovery in lions induced with ketamine. The recovery was the critical phase in the management of anaesthesia in genus Panthera as recovery should be rapid especially in free ranging animals so as to regain their mobility and ability to protect them from danger (Epstein et al., 2002; Jacquier et al., 2006; Khan et al., 2011).

\section{Monitoring}

The mean rectal temperature decreased significantly during maintenance and before recovery in both the lions induced with ketamine and propofol and maintained with isoflurane significantly $(\mathrm{p}<0.01)$ and the decrease was more marked $(\mathrm{p}<0.01)$ in lions induced with propofol. The reduction in the rectal temperature during maintenance and before recovery could be attributed to depression of thermoregulation, general anaesthesia, inhibition of skeletal muscle movement and reduction in metabolic rate (Tomizawa et al., 1997; Ali, 2005; Fahlman, 2005; Vesal and Naeini, 2007; Sontakke et al., 2009; Wenger et al., 2010). The marked reduction in propofol induced lions could be attributed to the peripheral dilatation of cutaneous blood vessels and peripheral pooling of blood due to the depression of central vasomotor action. No incidence of hypothermia was noticed as observed by Quandt (2005) in medetomidine-ketamine anaesthesia in lions.

The decrease in heart rate was highly significant $(\mathrm{p}<0.01)$ in lions induced with ketamine. The mean heart rate increased $(p<0.01)$ in both the groups before recovery.

The reduction in heart rate during maintenance in both groups of lions could be attributed to decrease in carotid sinus and baroreceptor reflex response, the central or peripheral suppression of sympathetic trunk, increased vagal activity and direct depressive action of xylazine on cardiac pacemaker and withdrawal of sympathetic tone. Ketamine had the tendency to increase the heart rate due to the inhibitory effect on the vagal component of baroreceptor reflex, selective positive ionotropic influence on heart muscle independent of reflexogenic autonomic nervous system, increased sympathetic tone, release of catacholamines from the peripheral tissues stores, stimulation of central nervous system, increased calcium influx and over flow of increased electrical activity in the limbic-hypothalamic centers upon the autonomic system via medullary centers (Nayak et al., 1997). The cardio stimulatory effect ketamine was moderated by propofol and isoflurane and the heart rate was stable in all the lions and the findings concurred with the findings of Quandt (2005), Tomizawa et al. (1997), Epstein et al. (2002), Ali (2005), Fahlman (2005) and Sontakke et al. (2009). Vesal and Naeini (2007) reported 55 to 65 beats per minute as the normal heart rate in lions and thus the heart rate was maintained within the normal range in the present study.

The electrocardiogram revealed normal sinus rhythm during the study except reduction in heart rate (Robinson and Benirschke, 1961).

Statistical analysis revealed highly significant $(\mathrm{p}<0.01)$ reduction in mean respiratory rate after induction and during maintenance in both the groups. The mean respiratory rate increased in both the groups before recovery.

The reduction in respiratory rate could be attributed to the combined effects of xylazine and ketamine (Wagner et al., 2010), propofol (Epstein et al., 2002) and isoflurane. In the present study the respiratory rate was maintained within the normal limits (Vesal and Naeini, 2007). The findings of the present study concurred with the findings of Ofri et al. (1998).

The reduction in $\mathrm{SpO}_{2}$ was highly $(\mathrm{p}<0.01)$ significant in both the groups after induction and before recovery.

The reduction in $\mathrm{SpO}_{2}$ following ketamine administration could be attributed to the direct relaxant effect of ketamine on bronchial smooth muscle and hypoventilation. Propofol anaesthesia also decreased $\mathrm{SpO}_{2}$ due to the reduction in respiratory rate. The finding of the present study concurred with previous reports (Wenger et al. (2010).

\section{CONCLUSION}

The study revealed that higher dose $(\mathrm{p}<0.05)$ of xylazine and ketamine was required in sub-adult lions than adult lions for immobilization. Similarly lions required higher dose $(p<0.05)$ of xylazine and ketamine than lioness for immobilization irrespective of body weights. The absence of ear flick reflex could be an indicator for safe approach for which the time factor between recumbency and absence of 
OPEN OACCESS

ear flick reflex and the requirement of further incremental doses of xylazine and ketamine to abolish the ear flick reflex should be considered judiciously. Custom made medical grade silicon plain endotracheal tubes $30 \mathrm{~mm}$ ID and above could easily be used for intubation in lions induced with propofol by oropharyngeal digital palpation of glottis. Isoflurane at a concentration of 0.50 to 2.00 per cent in 100 per cent oxygen could be used for maintenance. Recovery from anaesthesia in lions induced with ketamine was smooth; whereas propofol induction provided smooth induction and good relaxation sufficient for digital palpation of glottis and intubation; but recovery was rarely associated with hind limb staggering. No adverse reaction or post-operative complication was noticed in the study.

\section{ACKNOWLEDGMENTS}

We thank the Dean, Madras Veterinary College and Director of Clinics, Tamil Nadu Veterinary and Animal Sciences University for the funds provided for the procurement of anaesthetics and surgical disposables.

\section{CONFLICT OF INTEREST}

We certify that there is no conflict of interest with any individual / organization regarding the material discussed in the manuscript.

\section{AUTHOR'S CONTRIBUTION}

Murugan Bharathidasan, Benjamin Justin William and Rajarathanan Thirumurugan planned and conducted the research. Ramamurthy Jayaprakash involved in the radiographic assessment. Ravi Sundar George and Thandavan Arthanari Kannan provided post-operative care. All the authors contributed in the preparation of the manuscript.

\section{REFERENCES}

-Adnet F, Borron SW, Racine SX, Clemessy JL, Founier JL, Plaisance P, LapandryC (1997). The intubation difficulty scale (IDS). Anaesthesiol. 87: 1290-1297. http://dx.doi. org/10.1097/00000542-199712000-00005

-Ali M (2005). Propofol or ketamine as maintenance agents in xylazine-ketamine induced captive lions. M. V. Sc., thesis submitted to Tamil Nadu Veterinary and Animal Sciences University, Chennai, India.

-Bednarski R, Harvey R, SargnetB (2011). AAHA Anaesthesia guidelines for dogs and cats. J. Am. Hosp. Assoc. 47(6): 377385. http://dx.doi.org/10.5326/JAAHA-MS-5846

-Epstein A, White R, Horowtiz IH, Hass PH, Ofri R (2002). Effects of propofol as an anaesthetic agent in adult lions (Panthera leo): a comparison with two established protocols. Res. Vet. Sci. 72: 137-140. http://dx.doi.org/10.1053/ rvsc. 2001.0535

-Fahlman A (2005). Anaesthesia of wild carnivores and primates.
Physiological effects and reversibility of medetomidine and dissociative anaesthetics. Licentiate thesis submitted to Swedish University of Agricultural Sciences, Uppsala.

-Fahlman A (2008). Advances in wildlife immobilization and anaesthesia. Clinical and physiological evaluation in selected species. Doctoral thesis submitted to Swedish University of Agricultural Sciences, Uppsala.

- Gatesman T, Wiesner H (1982). Immobilization of Polar (Thalarctos maritimus) and Brown (Ursus arctos) bears using etorphine and xylazine.J. Zoo Anim. Med.13: 11-18. http:// dx.doi.org/10.2307/20094555

-Gunkel C, Lafortune M (2008). Felids, In: Fowler, M. and R. E. Miller, eds. Zoo and Wild Life Animal Medicine: Current therapy, $6^{\text {th }}$ ed. WB Saunders, Philadelphia, 443-457.

-Hashizaki F, Kohno N, Narushima E, Tashiro K, Inoue M, Komine T, Yamakawa K, Takagi A, Saitoh M (1998). Contraception of vasectomy procedure for male lions, Panthera leo, at Tama Zoological Park [Japan]. J. Japanese Assoc. Zool. Gardens Aqua. 22(4): 100-103.

- Jacquier M, Aarhaug P, Arnemo JM (2006). Reversible immobilization of free - ranging African lions (Panthera leo) with medetomidine - tiletamine-zolazepam and atipamezole. J. Wildl. Dis. 42: 432-436. http://dx.doi. org/10.7589/0090-3558-42.2.432

-Khan S, Hassan AMM, Uddin MB, Rahman ZMM, Yasin G, Epstein JH (2011). Caesarean of lion (Panthera leo) at Dulahajra Safari Park, Bangladesh. Open Vet. J. 1:10-12.

-Kock D, Burroughs R (2012). Chemical and physical restraint of wild animals: A training and field manual for African species. Edn.II. IWVS, South Africa.

-Leonardi L, Lepri E, Nannarone S, Olivieri O, Mechelli L (2014). Fobroblastic osteosarcoma in a lion (Panthera leo). Open Vet. J. 4(1): 1-3.

- Meltzer DGA (1999). Medical management of a cheetah breeding facility in South Africa. In: Zoo and Wild Life Animal Medicine: Current therapy, Fowler, M. and R. E. Miller, eds., $4^{\text {th }}$ ed. WB Saunders, Philadelphia. 415-435.

-Nayak S, Mohanty J, Patro KC, Pradhan PC (1997). Xylazineketamine anaesthesia for vasectomy operations in lions (Panthera leo) at Nandankanan Zoological Park, Orissa. Indian Vet. J. 74: 878-879.

- Ofri R, Horowitz I, Jacobson S, Kass PH (1998). The effects of anesthesia and gender on intraocular pressure in lions (Panthera leo). J. Zoo Wild1. Med. 29(3): 307-310.

-Olatunji-Akioye AO Omobowal OT Olaifa AK J. O. Abiola JO (2010). Tail docking in an African lion (Panthera leo). Israel J Vet Med. 65(2): 75-76.

-Quandt (2005). The immobilization of African lions (Panthera leo) with medetomidine / ketamine in comparision with tiletamine / zolazepam and phencyclidine. Verh. Berl. Int. Symp. Erkr. Zoot. 42: 41-52.

- Robinson PT, Benirschke K (1961). Removal of a cutaneous dermoid in an African lion (Panthera leo). J. Zoo. An. Med. 12: 85-86. http://dx.doi.org/10.2307/20094527

-Schaller GB (1972). The Serengeti lion - A study of predator pray relations. University of Chicago Press, Chicago.

-Sontakke SD, Umapathy G, Shivaji S (2009). Yohimbine antagonizes the anaesthetic effects of ketamine-xylazine in captive Indian wild felids. Vet. Anaest. Analg. 36: 34-41. http://dx.doi.org/10.1111/j.1467-2995.2008.00427.x

-Stander PE, Morkel P (1991). Field immobilization of lions using dissociative anaesthetics in combination with sedatives. Afr. J. Ecol. 29: 137-148. 
- Steeil JC, Schumacher J, Seibert R, Tobias K (2012). Cefovecin (Convenia) for the treatment of septic peritonitis in a female lion (Panthera leo). J. Zoo Wildl. Med. 43(3): 678-681. http://dx.doi.org/10.1638/2012-0038R.1

- Swan GE (1993). Drugs used for the immobilization, capture and translocation of wild animals. In: McKenzie AA, ed. The Capture and Care Manual. Wildlife Support Services, Pretoria, 2-64.

-Tomizawa N, Tsujimoto T, Itoh Ogino T, Nakmura K (1997). Chemical restraint of African lions (Panthera leo) with medetomidine-ketamine. J. Vet. Med. Sci. 59(4): 307-310. http://dx.doi.org/10.1292/jvms.59.307

-Titze IR, Fitch WT, Hunter EJ, Alipour F, Montequin D, Armstrong DL, McGee J, Walsh EJ (2010). Vocal power and pressure-flow relationships in excised tiger larynges. J. Exp. Biol. 213: 3866-3873. http://dx.doi.org/10.1242/ jeb.044982

-Van Wyk TC, Berry HH (1986). Tolazoline as an antagonist in free-living lions immobilised with a ketamine-xylazine combination. J. S. Afr. Vet. Ass. 4: 221-224.

-Vesal N, Naeini AT (2007). Immobilization and anaesthesia of African lion (Panthera leo) 5 cases. Iranian J. Vet. Surg. 2(3): 77-83.

-Wack RF (2003). Felidae. In: Fowler, M. E and Miller, R. E. eds. Zoo and Wild Animal Medicine. 5th ed. W. B. Sounders, St. Louis. 491-501.

-Wenger S, Buss P, Joubert L, Steenkamp J, Shikwambana P, Hatt JM (2010). Evaluation of butorphanol, medetomidine and midazolam as a reversible narcotic combination in free - ranging African lions (Panthera leo). Vet. Anaesth. Analg. 37(6): 491-500. http://dx.doi.org/10.1111/j.14672995.2010.00569.x

-Weissengruber GE, Forstenpointner G, Peters G, KübberHeissand A, Fitch WT (2002). Hyoid apparatus and pharynx in the lion (Panthera leo), jaguar (Panthera onca), tiger (Panthera tigris), cheetah (Acinonyx jubatus) and domestic cat (Felis silvestrisf. catus). J. Anat. 201(3):195-209. http://dx.doi.org/10.1046/j.1469-7580.2002.00088.x 